\title{
Analysis of factors responsible for intrauterine fetal death in rural pregnant women at tertiary care centre of Northern India
}

\author{
Shaveta Garg, Naina Kumar*
}

Department of Obstetrics and Gynecology, Maharishi Markandeshwar Institute of Medical Sciences and Research, Ambala, Haryana, India

Received: 10 July 2017

Accepted: 05 August 2017

\section{*Correspondence:}

Dr. Naina Kumar,

E-mail: drnainakumar@gmail.com

Copyright: () the author(s), publisher and licensee Medip Academy. This is an open-access article distributed under the terms of the Creative Commons Attribution Non-Commercial License, which permits unrestricted non-commercial use, distribution, and reproduction in any medium, provided the original work is properly cited.

\section{ABSTRACT}

Background: Intrauterine fetal death (IUFD) is a tragic event for both the parents and obstetrician. Objectives of current study were to study the underlying etiology of Intra Uterine Fetal Death (IUFD) that can be helpful in formulating the preventive measures.

Methods: This study was conducted over a period of one year from April 2016 till March 2017 at a tertiary rural care hospital. All patients with diagnosed IUFD at $>24$ weeks of gestation were included in the study.

Results: Total eighty patients were admitted with diagnosis of intrauterine fetal death. Among these majority 58 $(72.5 \%)$ were multigravida and only $22(27.5 \%)$ were primigravida. Maximum number of patients, $61(72.5 \%)$ were between age group of 20-30 years. Maximum number of IUFD were reported between 36-40 weeks of gestation $(36.25 \%)$. Most of fetal deaths were due to preventable conditions like hypertensive disorders of pregnancy $(28.75 \%)$, severe anemia (15\%), abruptio placenta (11.25\%), and rupture uterus $(10 \%)$. Out of these patients $68(85 \%)$ delivered vaginally and 7 patients were delivered by LSCS.

Conclusions: The present study emphasizes the role of health education, regular antenatal checkups, early detection of complications and hospital delivery to reduce the overall preventable IUFD.

Keywords: Intrauterine fetal demise, Placenta, Still birth

\section{INTRODUCTION}

Intrauterine fetal death and still birth is a cause of stress for both parents and the treating doctors. The gestational age at which intrauterine fetal demise is considered as still birth is different in various countries. In some countries, still birth is considered after 16 weeks of gestation while others consider fetal death as late as 28 weeks. ${ }^{1}$

The prevalence of IUFD has been decreased in developed countries but it still remains very high in underdeveloped and developing countries. ${ }^{1}$ Rate of incidence varies in different parts of the world. Annually 2.6 million stillbirths occur worldwide in 2015 with average still birth rate of 18.4 per 1000 births and the developing countries of Asia and sub Saharan Africa together are responsible for two -thirds of the world's stillbirth burden. ${ }^{2}$ Rate of still births in India ranges from 20 to 66 per thousand births in different states. ${ }^{3}$ It is also found that inadequate healthcare, lack of antenatal checkups, illiteracy and socio-cultural factors contribute to the increase rate of stillbirths in India.

Early neonatal deaths and stillbirths usually have obstetric causes, and can be prevented by timely obstetric care. $^{3}$ Anemia, hypertensive disorders of pregnancy, accidental hemorrhage are leading causes of IUFD and whereas prematurity, birth asphyxia, congenital 
malformations and cord prolapse leads to intrapartum stillbirths. ${ }^{4,5}$

\section{METHODS}

The present study was carried out in the department of Obstetrics and Gynecology of a rural tertiary care centre of Northern India over a period of one year after taking informed written consent and proper ethical committee approval.

\section{Inclusion criteria}

All antenatal patients who presented in Labour Room with diagnosis of intrauterine fetal demise after 24 weeks of gestation were considered as cases.

\section{Exclusion criteria}

- Patients presenting before 24 weeks of gestation.

- Patients who delivered fetus weighing less than 500grams.

- Patients who delivered outside.

A detailed history was taken including sociodemographic factors, obstetrical history, past and present medical history and any aggravating factor leading to fetal demise. History related to any drug intake and radiation exposure was noted. Blood pressure, weight, height and all basic investigations including ultrasonography were recorded to look for cause of fetal death and confirm the diagnosis of intrauterine fetal demise. Investigations included $\mathrm{ABO}$ and $\mathrm{Rh}$ grouping, VDRL, fasting and postprandial blood sugar, urea, creatinine estimation, thyroid profile, viral serology. The gestational age, mode of delivery, sex and birth weight of fetuses were noted. Final analysis was done using SPSS 20 version software.

\section{RESULTS}

During the study period, eighty patients were admitted with diagnosis of intrauterine fetal death. Among these majority 58(72.5\%) were multigravida and only $22(27.5 \%)$ were primigravida.

Table 1: Demographic factors.

\begin{tabular}{|lll|}
\hline Details & Number & $\%$ \\
\hline Unregistered cases & 71 & 88.75 \\
\hline Registered cases & 9 & 11.25 \\
\hline Age & & \\
\hline$<20$ years & 3 & 3.75 \\
\hline 20-30 years & 61 & 76.25 \\
\hline 31-40 years & 15 & 18.75 \\
\hline$>40$ years & 1 & 1.25 \\
\hline Parity & & \\
\hline Primigravida & 22 & 27.5 \\
\hline Multigravida & 58 & 72.5 \\
\hline
\end{tabular}

Maximum number of patients, $61(72.5 \%)$ were between age group of $20-30$ years and only 3 patients were less than 20 years old, as shown in Table 1 .

Table 2: Gestational age at time of admission.

\begin{tabular}{|lll|}
\hline Gestational age in weeks & Number & $\%$ \\
\hline $24-30$ & 19 & 23.75 \\
\hline $31-35$ & 27 & 33.75 \\
\hline $36-40$ & 29 & 36.25 \\
\hline$>40$ & 5 & 6.25 \\
\hline
\end{tabular}

Maximum number of IUFD were reported between 36-40 weeks $(36.25 \%)$ of gestation (Table 2). Only $6.25 \%$ patients presented after 40 weeks of gestation.

Table 3: Causes of intrauterine fetal demise (IUFD).

\begin{tabular}{|lll|}
\hline Cause of IUFD & Number & $\%$ \\
\hline \multicolumn{2}{|l|}{ Hypertensive disorders of pregnancy } & \\
\hline Gestational hypertension & 6 & 7.5 \\
\hline Pre-eclampsia & 10 & 12.5 \\
\hline Eclampsia & 7 & 8.75 \\
\hline Severe anemia & 12 & 15 \\
\hline Antepartum hemorrhage & & \\
\hline Placenta previa & 4 & 5 \\
\hline Abruptio placenta & 9 & 11.25 \\
\hline Postmaturity & 1 & 1.25 \\
\hline Congenital malformations & 4 & 5 \\
\hline Rupture uterus & 8 & 10 \\
\hline Obstructed labor & 3 & 3.75 \\
\hline Hepatorenal failure & 2 & 2.5 \\
\hline Infectious disease & 4 & 5 \\
\hline Unexplained & 14 & 17.5 \\
\hline
\end{tabular}

*in some cases, there was more than one underlying cause

In current study, in 14 patients cause for intrauterine death was not clear. Most of fetal deaths were due to preventable conditions like hypertensive disorders of pregnancy in $28.75 \%$ out of which eclampsia was present in $8.75 \%$, severe anemia in $15 \%$, abruptio placenta in $11.25 \%$ and rupture uterus in $10 \%$ cases.

Table 4: Mode of delivery.

\begin{tabular}{|llll|}
\hline $\begin{array}{l}\text { Mode of delivery } \\
(\mathbf{n = 8 0})\end{array}$ & $\begin{array}{l}\text { Preterm } \\
\text { births }\end{array}$ & $\begin{array}{l}\text { Term } \\
\text { births }\end{array}$ & $\%$ \\
\hline LSCS & 1 & 7 & 10 \\
\hline $\begin{array}{l}\text { Vaginal delivery } \\
\begin{array}{l}\text { Laparotomy (rupture } \\
\text { uterus) }\end{array}\end{array}$ & 44 & 22 & 85 \\
\hline
\end{tabular}

Of these patients $68(85 \%)$ patients delivered by vaginal route and 8 patients required LSCS (3 patients with previous scar, 2 with abruption placentae and 3 with placenta praevia). Laparotomy followed by hysterectomy was done in 3 patients of rupture uterus in whom uterus could not be repaired. Among all these patients, eight 
patients required ventilatory support, out of which 4 succumbed to death.

\section{DISCUSSION}

Stillbirths occur mostly due to the causes which are preventable with proper antenatal care but still this is neglected in developing countries like India. Women in India have many difficulties in regular health check -ups due to accessibility, availability, affordability and quality of healthcare facilities available during pregnancy. ${ }^{3}$ Our hospital is a rural tertiary care referral centre and most of the women were referred after diagnosis of IUFD for further management. In present study, there were 80 patients who were admitted with diagnosis of IUFD and most of them $71(88.75 \%)$ were emergency admissions of unregistered patients and only $9(11.25 \%)$ were registered patients. Similar findings were reported by Choudhary A et al who found a higher incidence of stillbirths $(89.53 \%)$ in emergency admissions. ${ }^{1}$

Patel S et al and Korde NV et al had also reported a high incidence of $70 \%$ and $84.9 \%$ respectively of IUFD in unbooked patients as compared to booked patients. ${ }^{4,5}$ In patients who come for regular antenatal checkups, complications can be timely diagnosed and treated leading to better pregnancy outcome. ${ }^{6}$ In present study 3 $(3.75 \%)$ patients were less than 20 years of age, 61 (76.25\%) were between age of 21-30 years and 15 $(18.75 \%)$ were more than 30 years. Similar results were reported by Patel $\mathrm{S}$ et al. ${ }^{4}$ Frett et al and McClure E et al has also concluded that women of age more than 35 years have increased risk of fetal death. ${ }^{7,8}$ In present study incidence of IUFD was higher in multigravida 58 $(72.5 \%)$ as compared to primigravida. Korde NV et al and $\mathrm{S}$ Patel et al had also shown that parity influences the pregnancy outcome and incidence of stillbirths was higher in multigravida.,

In this study $19(23.75 \%)$ patients presented before 30 weeks of gestation with IUFD. Prematurity has been shown as another risk factor for fetal death by Patel $\mathrm{S}$ et al and Al Kadari et al. ${ }^{4,9}$ In present study, 50 (62.5\%) were between 25-32 weeks of gestational. In this study, the most common cause associated with IUFD was hypertensive disorders of pregnancy seen in $28.75 \%$ and among these $10(12.5 \%)$ patients had pre-eclampsia and $8.75 \%$ presented in emergency with eclampsia. Abruptio placenta accounted for $9(11.25 \%)$ cases in present study. PIH and eclampsia together contributed or $27(33.7 \%)$ cases and Abruptio placenta accounted for 10 (12.5\%) cases of IUFD in study conducted by Patel S et al. ${ }^{4}$ Anjali $\mathrm{C}$ et al reported PIH causes IUFD in $30 \%$ and abruption placenta in $10.4 \%$ cases which is comparable to our study. ${ }^{1}$ Korde $\mathrm{NV}$ et al reported the most common cause of IUFD as abruptio placenta seen in $21.9 \%$ and PIHeclampsia together in $18.7 \%$ cases. $^{5}$ According to Kotweg et al the most important cause for IUFD was growth restriction, emphasizing that role of placental is important for optimal fetal growth. ${ }^{10}$ Severe anemia was underlying factor in $12(15 \%)$ cases in our study which is comparable to $16 \%$ reported by Chaudhary A et al. ${ }^{1}$ Infectious diseases were encountered in $4(5 \%)$ patients out of which 3 cases were of malaria.

Chaudhary A et al reported maternal infections as a complicating factor in $7.62 \%$ pregnancies out of which there were five cases of clinically proven malaria and one case of pneumonia. ${ }^{1}$ In our study $8(10 \%)$ presented with rupture uterus due to handling by unskilled attendants and inappropriate use of misoprost and oxytocin. 3 (3.75\%) patients were referred from rural area due to obstructed labor leading to IUFD. Korde NV et al had reported obstructed labor in $1.1 \%$ cases. $^{5}$ According to a study conducted by McClure et al in low income countries $51 \%$ delivered at home, out of which $16 \%$ had no health care provider available at delivery and $34 \%$ had an unskilled attendant. ${ }^{8}$ Antenatal patients should be educated for regular antenatal checkups and institutional deliveries to decrease these complications.

The incidence of unexplained fetal demise is constant over the years and Chaudhary A et al has reported $19.5 \%$ fetal deaths as unexplained. ${ }^{1}$ In this study in 14 (17.5\%) fetal deaths no cause was detected. In our study, congenital malformation was present in $4(5 \%)$ cases. Chaudhary A et al and Patel Set al had reported fetal deaths due to congenital malformation in $10.5 \%$ and $2.5 \%$ respectively. ${ }^{1,4}$ In current study mode of delivery was vaginal route in $68(85 \%)$ patients which is comparable to studies conducted by others. Patel $\mathrm{S}$ et al and Korde NV et al had reported vaginal delivery in $91.2 \%$ and $73.1 \%$ cases respectively. ${ }^{4,5}$ Caesarean section was required in $8(10 \%)$ and hysterectomy was done in 4 $(5 \%)$ patients. Indication for hysterectomy was rupture uterus in 3 cases and 1 patient of placenta praevia due to uncontrolled bleeding even after taking all medical and surgical conservative measures. Caesarean section was required in $4(5 \%)$ in study conducted by Patel S et al. ${ }^{4}$

\section{CONCLUSION}

Most of women presented in emergency with IUFD and there was history of inadequate antenatal care. Majority of causes leading to IUFD like hypertensive disorders of pregnancy, eclampsia, abruption placentae and severe anemia can be prevented by regular health checkups by trained doctors. Congenital fetal malformations cannot be avoided but can be detected at an early gestation. We emphasize on health education, regular antenatal checkups, early detection of complications and hospital delivery so as to reduce the overall burden of perinatal mortality in coming future.

\section{ACKNOWLEDGMENTS}

Authors would like to thank Head of Department and my colleagues of Department of Obstetrics and Gynecology, MMIMSR for their constant support and guidance. 
Funding: No funding sources

Conflict of interest: None declared

Ethical approval: The study was approved by the Institutional Ethics Committee

\section{REFERENCES}

1. Choudhary A, Gupta V. Epidemiology of intrauterine fetal deaths: a study in tertiary referral centre in Uttarakhand. IOSR-JDMS. 2014;13(3):03-06.

2. Blencowe H, Cousens S, Jassir FB, Say L, Chou D, Mathers $\mathrm{C}$ et al. National, regional, and worldwide estimates of stillbirth rates in 2015 with trends from 2015: a systematic analysis. Lancet. 2016;4(2):98108.

3. Bhati DK. Stillbirths: A high magnitude public health issue in India. South East Asia J Public Health. 2013;3(1):3-9.

4. Patel S, Thaker R. Study of causes and complications of intra uterine fetal death (IUFD). Int J Reprod Contracept Obstet Gynecol. 2014;3(4):931-5.

5. Korde NV, Gaikwad P. Causes of stillbirth. J Obstet Gynecol India. 2008;58(4):314-8.

6. Richardus, Jan H, Graafmans, Wilco C. The perinatal mortality rate as an indicator of quantity of care in international comparison. Med Care. 1998;36(1):5466.

7. Fretts RC, Usher RH. Causes of fetal death in women of advanced maternal age. Obstet Gynecol. 1997;89:40.

8. McClure EM, Pasha O, Goudar SS, Chomba E, Garces A, Tshefu A et al. Epidemiology of stillbirth in low- middle income countries: a global network study. Acta Obstet Gynecol Scand. 2011;90(12):1379-85.

9. Al Kadari, Hanan T, Hani. Factors contributing to intra uterine fetal death. Arch Obstet Gynecol. 2012;286(5):1109.

10. Korteweg FJ, Gordijn SJ, Timmer A, Holm JP, Ravisé JM, Erwich JJ. A placental cause of intrauterine fetal death depends on the perinatal mortality classification system used. Placenta. 2008;29(1):7180.

Cite this article as: Garg S, Kumar N. Analysis of factors responsible for intrauterine fetal death in rural pregnant women at tertiary care centre of Northern India. Int J Reprod Contracept Obstet Gynecol 2017;6:4071-4. 